\title{
De que adianta aprender se não for para aplicar ou transmitir?
}

\author{
Edson Arpini Miguel, Letícia Cabrini Girotto, Adriana Lenita Meyer, Irinéia Baretta, Paulo Roberto \\ Donadio
}

\section{Resumo}

Introdução: A participação de grupos dentro da área da saúde, que tenham origem em cursos de graduação distintos, na prática docente, entende-se que o trabalho conjunto de pessoas de formações diferentes quando realizado com planejamento, objetivos definidos, orientado por competências, torna-se uma importante alternativa para o aprendizado e para a melhor atenção à saúde. Esta atividade de Práticas colaborativas é um o processo pelo qual pessoas em diversos níveis de conhecimento trabalham juntas, em pequenos grupos, com vistas a um objetivo comum. No Curso de Processos Educacionais na Saúde (PES) um espaço de aprendizagem colaborativa com interdependência positiva, responsabilização individual e habilidades interpessoais. Perrenoud utiliza o termo "trabalhar em equipe" quando fala das 10 Novas Competências para Ensinar (2000). Para a Organização Mundial da Saúde (OMS), Prática Colaborativa na atenção à saúde ocorre quando profissionais de saúde de diferentes áreas prestam serviços com base na integralidade da saúde, envolvendo os pacientes e suas famílias, cuidadores e comunidades para atenção à saúde da mais alta qualidade em todos os níveis da rede de serviços, a partir dos três grandes objetivos definidos pelo PES: (1) a formação de facilitadores, (2) utilização de metodologias ativas de ensino aprendizagem, (3) visando a melhoria da qualidade e segurança de atenção em saúde; Objetivo: descrever as atividades e reflexões produzidas no Curso de Processos Educacionais. Métodos: As reflexões descritas fazem parte da compilação de ações e atividades do referido curso em diálogo com vários autores, monitoradas por portfólio reflexivo, avaliação por pares e auto avaliação, além de avaliação formativa por parte da gestora de aprendizagem do grupo. Resultados/discussão: Basicamente, o trabalho consistiu em três cenários de ensino, em que as atividades sofreram influência direta do PES, aprimorando conhecimentos e ampliando a visão da metodologia até então utilizada. Os cenários foram: 1. Ambulatorial a. Pequenos grupos b. Reconhecendo as fronteiras ou limites de conhecimento e propondo estratégias de ensino como facilitador. c. Apresentando novas formas de avaliação d. Exercitando o feedback 2. Disciplina interprofissional a. Problematização utilizando o Arco de Maguerez b. Portfólio: como avaliação contínua de disciplina. c. Avaliação: sócio afetiva, psicomotora, pares e autoavaliação. 3. Hospitalar a. Revisão de prontuários: como e o que pesquisar, definindo prioridades. b. Comunicação com equipe e familiares c. Briefing e debriefing: com feedback apreciativo aos residentes. O PES proporcionou a possibilidade de discutir com profissionais de outras áreas aimportância de estratégias inovadoras que possam desenvolverprogramas para motivar a força de trabalho de forma ampla com o olhar para o serviço de saúde, conforme suas áreas de atuação. O referencial teórico mais importante quanto à estas práticas é O Marco para Ação em Educação Interprofissional e Prática Colaborativa(OMS 2010) que enfatiza a situação atual da colaboração interprofissional no mundo, identifica os mecanismos que resultam no trabalho em equipe colaborativo bem-sucedido e delineia uma série de itens para a ação que os formuladores de políticas podem aplicar em seu sistema de saúde local. Este trabalho procurou enfatizar que o termo Educação interprofissional pode ser utilizado quando duas ou mais profissões aprendem sobre os outros, com os outros e entre si para a efetiva colaboração e melhora dos resultados na saúde. Porém, tanto a atuação no PES, quanto a atuação diária nas instituições, necessita de referenciais teóricos, muitas vezes relegados a um segundo plano, quando da execução de projetos deste vulto. $\mathrm{Na}$ atividade escolar existem três elementos centrais, para que o desenvolvimento ocorra com sucesso: o estudante, o professor e a situação de aprendizagem. A 
busca por conhecimento sobre teorias de aprendizagem tentando aprimorar a dinâmica envolvida nos atos de ensinar e aprender, tentando explicar a relação entre o conhecimento pré-existente e o novo conhecimento, se mostrou uma das lacunas de conhecimento tanto do grupo PES, quanto nas atividades docentes. Mitre S M (2008) questiona: "Mas por que tem se tornado imperioso rediscutir os processos de ensino-aprendizagem necessários à formação para o trabalho em saúde?" Entre as respostas da autora, seleciona-se uma mais apropriada, embora complementar com as demais: "a configuração de uma nova modalidade de organização do espaço-tempo social, as sociedades de controle, o que torna imperiosa a adoção de uma postura crítica sobre a inscrição do sujeito no mundo - aqui incluído o trabalho - caracterizando um verdadeiro ato de resistência". Conhecer, mesmo que em linhas gerais as divisões das Teorias de aprendizagem do Behaviorismo, das chamadas Teorias de Transição classificadas como o inicio do cognitivo moderno até as Teorias Cognitivas, auxiliam a fundamentação que sustentam estas reflexões. Mereceu especial atenção, influenciando diretamente a prática, o tempo e a profundidade reservados à analise da Espiral Construtivista, metodologia problematizadora, em currículos que utilizavam metodologias ativas de ensino aprendizagem. Segundo Lima (2017), a experiência com a Espiral, revelou que, a partir do processamento de problemas, as questões de aprendizagem, elaboradas pelos estudantes, apresentavam maior articulação disciplinar do que o guia do tutor produzido pelos professores. Será possível utilizar esta metodologia em todos os momentos e com diferente número de pessoas? A utilização de grupos de até 10 pessoas permite que conheçamos de forma individual cada um dos participantes com oportunidade de oferecer feedback apropriado e em tempo adequado. O Pequeno Grupo se constitui quando existem pessoas que compartilham o mesmo ambiente, com objetivos em comum e que trabalham coletivamente para alcançá-los, estabelecendo metas e estratégias, e centrando-se na realização de tarefa. Nesse contexto os participantes assumem e adjudicam papéis, permitindo a visão diversificada e o desempenho crítico diante das situações reais, bem como a construção coletiva de atitude (des)alienantes. A prática no PES foi de extraordinária riqueza quando exercitada a facilitação, nas várias formas e momentos, mas principalmente, quando nos deparou-se com situações de embate teórico ou de relatos de experiência, e porque não, nos momentos de avaliação. A descrição destes "papéis" desenvolvidos por cada um está bem documentada em Pichon-Riviere (1998), em especial quando "denuncia os conteúdos latentes da grupalidade" embora tenham sido, inicialmente, os estudos Bion (2010) que trouxeram a tona a noção de cultura de grupo, considerando os conflitos existentes entre a mentalidade de grupo e os desejos individuais, afirmando que pode haver uma "mudança catastrófica", quando ideias novas promovem uma ruptura na mentalidade do grupo prevalente, para constituir uma nova. Finalmente, aquele autor, afirma que é na confluência das experiências individuais e coletivas que nasce o conteúdo que será manifestado pelo porta-voz do grupo. Diria-se: "Mas para pensar e fazer assim, tem que sair da caixinha." Quando nos reportamos a estes referenciais e de que forma exercitamos no PES, obrigatoriamente, nos vimos colocados de forma antagônica aos princípios de explicação do Paradigma Clássico (redução, separação e simplificação), pois ele unifica o que é múltiplo, quantifica o que é qualificável, simplifica o que é complexo. Outra visão, tende a ser ampliada na perspectiva do Paradigma da Complexidade, quando questiona/perturba o paradigma "clássico", trazendo a ideia de Morin (2002), sobre a complexidade das relações: antireducionista aberta e dialética para que possa ser dialógica. Trazendo a relação de convívio e inseparabilidade dos antagônicos, dos concorrentes, dos contrários. Conclusão: Participar do PES, trouxe a possibilidade de construir solidas relações em função do trabalho individual e coletivo, mostrando a relevância da comunicação entre componentes, observando diferentes níveis de compreensão, com o desenvolvimento da escuta. Não faltaram embates e demonstrações claras de diferenças de pontos de vista e conceitos, porém, ideias defendidas e respeitadas, de forma a não prejudicar os relacionamentos futuros, mas numa perspectiva dialógica.

Descritores: Educação, Avaliação, Saúde, ensino serviço de saúde. 